Laís M. S. N. Leite ${ }^{1,2}$; Sarah K. French ${ }^{1,3,4}$; Christopher A. Searcy ${ }^{1,5}$; Shannon J. McCauley ${ }^{1,3}$

\title{
Forest edges and their effects on the arrival of dragonflies at north-temperate experimental ponds
}

\author{
https://doi.org/10.23797/2159-6719_24_2
}

Received 15 October 2020; Accepted 29 October 2020; Published 27 May 2021

\begin{abstract}
The matrix, an environment in the landscape that individuals move through but do not reside in, can affect species dispersal and the arrival of individuals at habitat patches. Elements around this matrix that provide refuge or resources may shape the arrival of animals at habitat patches, even when those patches are equivalent in quality. Adult dragonflies (Odonata: Anisoptera) frequently use open terrestrial environments during movement and dispersal in north-temperate regions; however, they can also roost along forest edges. Because of the potential value of forest edges to adult dragonflies, we tested whether pond proximity (i. e., connectivity) to multiple forest edges was positively related to the abundance or diversity of arriving dragonflies. We observed dragonflies arriving at 9 experimental pond sites located within an open field landscape in Ontario, Canada. Experimental ponds differed in their distance to source ponds and to forest edges, a potential refuge for dragonflies. We found no effect of connectivity to forest edges or distance to source ponds on the abundance or diversity of dragonflies arriving at a site. Dragonfly dispersal was therefore not limited at the spatial scale of our study ( $<305 \mathrm{~m}$ to source ponds). In addition, dragonflies did not seem to discriminate among sites based on the amount of nearby forest edge, although all sites within the generally open landscape had at least some forest edge in close proximity $(10-79 \mathrm{~m})$. Our results provide greater insight regarding the decisions that dragonflies make in response to landscape elements while dispersing to reproductive habitats.
\end{abstract}

Keywords: Odonata, dragonfly, Anisoptera, forest, community assembly, landscape matrix

\section{Introduction}

Communities can be shaped by the landscape context in which habitat patches are situated (Wiens, 2002). The dominant type of environment surrounding a habitat patch (referred to as the matrix) is traditionally considered to be both unable to support species' habitat and resource needs and to uniformly affect the dispersal of individuals among habitat patches (Kupfer et al., 2006). However, a landscape can be heterogeneous, consisting of multiple landscape elements such that the [dominant] matrix and habitat patches are mixed with corridors and other smaller landscape elements (e.g., Chardon et al., 2003). These smaller landscape elements can encourage or impede movement and dispersal (e.g., Fahrig, 2001; Chardon et al., 2003; Eycott et al., 2012; Keller et al., 2012), and affect individuals' choices of habitat and resulting distributions (e.g., Baguette \& Van Dyck, 2007; Kadoya \& Washitani, 2012). However, few studies consider the use of multiple landscape elements

\footnotetext{
1 Department of Biology, University of Toronto Mississauga, 3359 Mississauga Rd., Mississauga, ON L5L 1C6 Canada. [shannon.mccauley@utoronto.ca]

2 Current address: Laboratório de Limnologia, Ecotoxicologia e Ecologia Aquática, Instituto de Ciências Biológicas, Universidade Federal de Minas Gerais-UFMG, Belo Horizonte, MG, Brazil. [lah.sacchetto@hotmail.com]

3 Department of Ecology and Evolutionary Biology, University of Toronto, 25 Willcocks Street, Toronto, Ontario, Canada M5S 3B2

4 Current address: Department of Biology, York University, 4700 Keele Street, Toronto, Ontario, Canada M3J 1P3. [Corresponding Author: sarahkathrynfrench@gmail.com]

5 Current address: Department of Biology, University of Miami, 1301 Memorial Drive, Coral Gables, FL 33 146, USA. [casearcy@bio.miami.edu]
} 
by organisms when determining species' distributions or how communities assemble (Kadoya \& Washitani, 2012; but see Cormont et al., 2016).

The isolation of habitats from potential sources of colonists, whether by distance or due to a matrix that is difficult to traverse, can limit diversity by restricting dispersal and gene flow (MacArthur \& Wilson, 1967; Damschen et al., 2006; Haddad et al., 2015). In contrast, a matrix that facilitates movement may increase access to habitat patches for a diversity of species (Donald \& Evans, 2006; Prugh et al., 2008). For example, several butterfly species reproduce on host plants that occur in meadow patches within a forested matrix (Ricketts, 2001). However, in this case, the forest matrix is actually a mosaic of different tree species that range from permeable willow thickets to impermeable conifers (Ricketts, 2001). The willow matrix can therefore increase connectivity between disconnected meadow patches in comparison to other forested matrix types (Ricketts, 2001). Thus, elements in the landscape that surround a habitat may play a more prominent role in colonization than simply the distance between habitats or the coarse classification of the intervening matrix (Haslem \& Bennett, 2008; Keller et al., 2012).

Insects with complex life cycles often use different environments across their multiple life history stages (Debinski et al., 2001). Larval dragonflies (i.e., Odonata: Anisoptera; hereafter referred to as 'dragonflies') are restricted to aquatic habitat patches, but larval distributions across these patches are shaped not only by local factors such as the presence of fish predators (Johansson \& Brodin, 2003) but also by adult selection of open canopy aquatic habitats for reproduction (Remsburg et al., 2008; French \& McCauley, 2018). Before selecting reproductive habitat, however, adult dragonflies must traverse and respond to elements in the terrestrial landscape. As with butterflies, an open matrix can facilitate the movement and dispersal of some dragonfly species (French \& McCauley, 2019), whereas the likelihood of forests impeding movement depends on spatial scale (Chin \& Taylor, 2009). Forests do not appear to impede small-scale $(<700 \mathrm{~m})$ dispersal, but they can restrict the dispersal of some dragonfly species at larger spatial scales (700-1400 m; Chin \& Taylor, 2009), likely depending on the size and distribution of forests (e.g., Goodwin \& Fahrig, 2002). Forest edges can be important ecotones for many species, and may provide dragonflies with roosting sites, protection from predators, and/or food resources (e.g., Corbet, 2004; Morris et al., 2010; Schlinkert et al., 2016). Other taxa exhibit similar preferences for forest edges, including several bat species that use forest edges for foraging due to their high insect abundances (Morris et al., 2010), and some bird species that preferentially use forest edges for nesting (Brand \& George, 2001). Dragonflies have been observed to use forest edges for foraging as well as roosting (Corbet, 2004; Timofeev, 2016) and may use forest edges to different extents based on their latitudinal distribution (Corbet, 2006). At higher temperate latitudes, dragonflies are less likely to prefer forest interiors due to colder temperatures, whereas at tropical latitudes, the warmer forest interiors can provide more refuge (Corbet, 2006). At temperate latitudes, forest edges may facilitate the warming of dragonflies in the morning and throughout the day, whether they prefer open or more forested environments, and may protect species that prefer open areas while roosting or foraging in windy conditions (Corbet, 2004, 2006). Thus, for some species of dragonfly in temperate regions that generally prefer open environments, the availability of nearby forest edges for roosting and foraging may be important when colonizing or visiting reproductive habitats.

To address how terrestrial landscape elements affected the arrival of dragonflies at aquatic reproductive habitats in temperate regions, we monitored adult dragonflies (Anisoptera) arriving at newly created experimental ponds. These ponds were all situated within an open field matrix, which facilitates dragonfly movement (Chin \& Taylor, 2009; French \& McCauley, 2019), but varied in their distance to both source ponds and forest edges (Figure 1). We tested whether the landscape context of aquatic habitat patches (i. e., their proximity to forest edges) affected dragonfly arrival at these ponds, as adult dragonflies may evaluate the terrestrial landscape for additional habitat before or during the evaluation of an aquatic habitat. We expected that the abundance, richness, and species diversity of dragonfly visitors would be greatest at ponds closest to forest edges due to ease of accessing roosting habitat (a daily requirement) for species that roost in trees. We did not expect the distance between experimental ponds and source ponds to impact either dragonfly abundance or diversity due to the small spatial scales examined in relation to dragonflies' dispersal capabilities. 


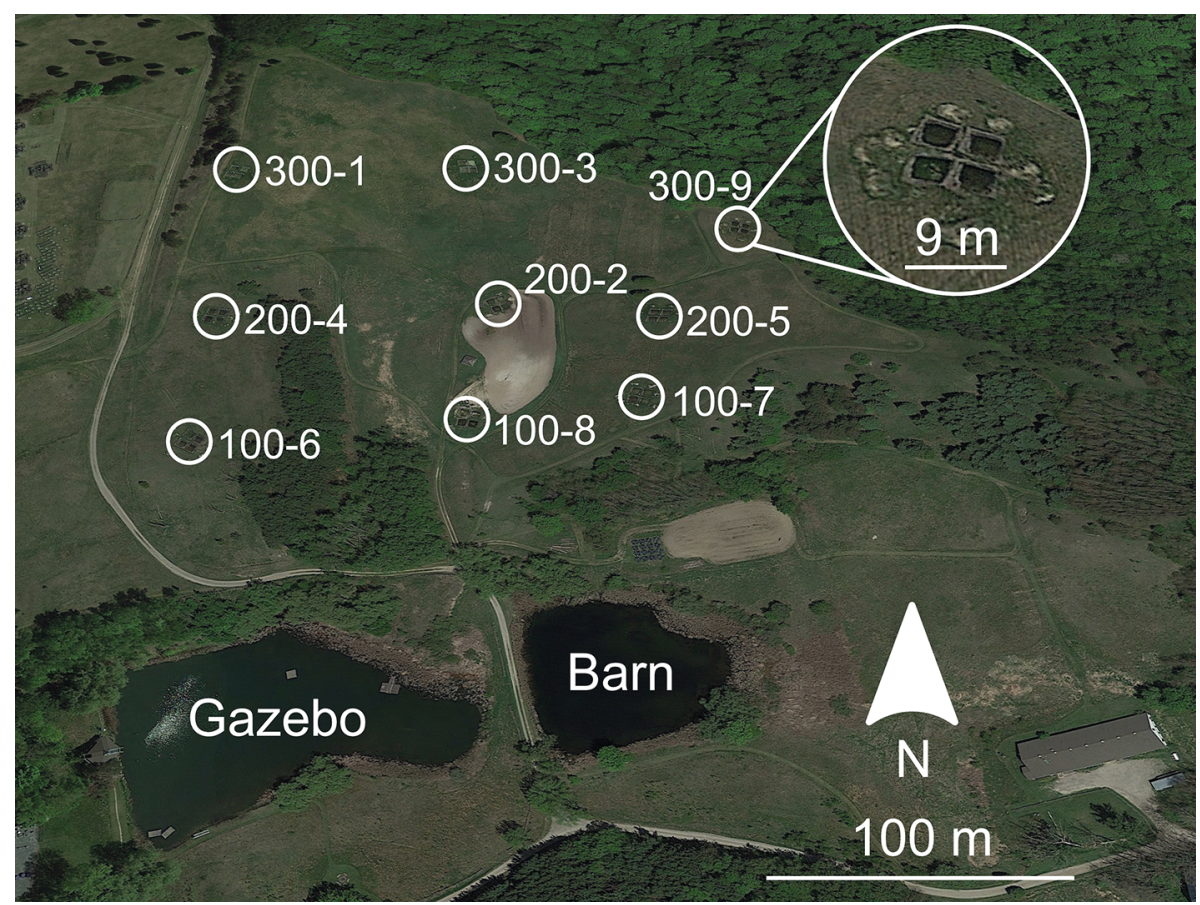

Figure 1. Map of source ponds (Gazebo and Barn Ponds) and experimental pond sites (circled in white and labelled 100,200 , or 300 based on approximate distance $(\mathrm{m})$ from source ponds and hyphenated with a number where 1 is least connected and 9 most connected to forests) at the Koffler Scientific Reserve. Pond sites, each containing four ponds (inset circle), are arranged in three transects away from the source ponds. The map was created using Google Earth Pro data from 2016.

\section{Materials and Methods}

\section{Study system}

Our study was conducted at the Koffler Scientific Reserve (King City, Ontario, Canada, $44.03^{\circ} \mathrm{N}$, $79.53^{\circ} \mathrm{W}$ ), a protected area with a mix of wetlands, forests, and old fields. There are three main ponds at the Koffler Scientific Reserve: two large neighbouring ponds with fish (Gazebo Pond and Barn Pond; Figure 1) that served as potential sources of colonists in our experiment, and a smaller fishless pond (Dufferin Pond) that is $\sim 500 \mathrm{~m}$ away from the others. Thirty-six small experimental ponds were constructed in the summer of 2014 (filled June 29-July 4, 2014) in old fields to the north of Gazebo and Barn Ponds. These experimental ponds were built to allow for a variety of studies on the effects of habitat isolation on the community assembly of freshwater organisms, with four replicate ponds at each site and spanning nine sites. Ponds were arranged in three transects away from the source ponds, at distances of approximately $100 \mathrm{~m}, 200 \mathrm{~m}$, and $300 \mathrm{~m}$ from the source ponds (Figure 1). Each pond was approximately $4 \times 4 \mathrm{~m}$ with a shallow littoral zone at the southern end and a deeper section at the northern end (average depth at deepest point: $0.72 \mathrm{~m}$ ), and ponds within a site were separated by $\sim 1-2 \mathrm{~m}$. The experimental ponds were filled with water from Barn Pond that was filtered through a $30 \mu \mathrm{m}$ water filter, preventing the transfer of most organisms to the new ponds. Each pond was then inoculated with a $0.75 \mathrm{~L}$ sample of zooplankton collected from Gazebo and Barn Ponds on July 8, 2014. While the four ponds may serve as independent replicates for some taxa with more limited mobility, after observing the adult dragonflies visiting these ponds we decided that the observations from all four ponds at a site should be combined, because an individual dragonfly often visited multiple ponds within a cluster in quick succession.

The landscape between the source and experimental ponds was dominated by an open [old] field matrix with tall perennial vegetation interspersed with forested landscape elements (Figure 1). Two 
small plowed plots are present in the matrix beside Barn Pond and in the center of the experimental pond set-up, which are occasionally used for growing small crops and housing mesocosm experiments, respectively (light bare patches in Figure 1). Although dragonflies may have originated from farther away than our two focal source ponds, particularly migratory species such as Tramea lacerata and Anax junius, we decided to base the distance to source pond on the closest potential source pond (111-304 m away), which was presumably the dominant source of colonists. As a result, Dufferin Pond was not considered to be a source pond, as it was in all cases farther away from the experimental ponds than Gazebo and Barn Ponds, and also contained a subset of the dragonfly community present at Gazebo and Barn Ponds (McCauley, unpublished data). The vegetation surrounding the experimental ponds included grasses and forbs, providing sufficient vegetation for dragonflies to perch on near the ponds and in the field matrix. Some patches of bare soil were present directly adjacent to the ponds due to their recent construction. Forest edges were a minimum of $10-79 \mathrm{~m}$ and maximum of $254-452 \mathrm{~m}$ away from experimental ponds. We used a connectivity metric that incorporated distances to all forest edges that could be accessible to flying dragonflies, to better represent what a dragonfly might perceive and/or interact with in the landscape. Distances to forest edges were measured using the LandscapeElement plugin (French \& French, unpublished method) for Fiji (a program based on ImageJ; Schindelin et al., 2012), at $1^{\circ}$ increments in $360^{\circ}$ directions from the edge of each site, and distance in pixels was converted to distance in $\mathrm{m}$. The 360 distance measurements were used to create a connectivity metric for each site to forest edges based on Hanski's index of connectivity (1994):

$S_{i}=\sum_{j \neq i} \exp \left(-\alpha d_{\mathrm{ij}}\right) A_{j}$

where $\alpha$ is the reciprocal of the mean dispersal distance of a species, $d_{\mathrm{ij}}$ is the distance between the edge of the site and the closest forest edge, and $A_{\mathrm{j}}$ is the area of the forest edge used by a dragonfly at a single location (McCauley, 2006). We considered the area to be $1 \mathrm{~m}^{2}(1 \mathrm{~m}$ deep $\times 1 \mathrm{~m}$ wide), as we assumed dragonflies would only use the very edge of the forest for roosting or foraging. Multiple mean dispersal distances of dragonflies were tested, including $500 \mathrm{~m}, 1000 \mathrm{~m}, 2000 \mathrm{~m}$, and $2700 \mathrm{~m}$ (McCauley, 2006). However, we only report results using $1000 \mathrm{~m}$, as variation in $\alpha$ did not impact our findings. Connectivity to source ponds was measured simply as the distance from each site to the edge of the closest source pond using Google Earth Pro.

\section{Adult dragonfly observations}

We observed dragonflies arriving at each site containing the newly created experimental ponds. Observations were made on a total of 19 sunny days between July 10-August 8, 2014. Each observation day consisted of a single observer (LMSNL) spending 10 minutes at each of the nine sites (i. e., $64 \mathrm{~m}^{2}$ of water surface area and $\sim 81 \mathrm{~m}^{2}$ including the space among ponds) during the afternoon (12 h00-17 h00), starting at a random site and then moving to the next closest site. All surveys were conducted visually, using binoculars to facilitate detection and identification when necessary. Dragonflies were recorded as visiting a site if they were observed in close proximity to a pond $(\sim 1 \mathrm{~m})$ or coming in contact with a pond (e.g., ovipositing in the pond), but with at least some degree of interaction with the pond (i.e., dragonflies flying over the pond that did not stay at the pond were not counted). All dragonflies present at the ponds were identified to species (Dunkle, 2000; Mead, 2003). Because of the close proximity of the four experimental ponds within a site, each site was treated as a single experimental unit. From our counts, the total abundance of dragonfly visitors per species to each site was determined and pooled across the entire sampling season. These counts were not intended to represent absolute abundances at the study sites, as they both missed many individuals that visited the study sites outside of the observation periods and may have doublecounted the same individual between days. Rather, these counts were meant to represent relative abundances among sites, as the estimation method remained identical across all ponds. Within a sampling day, we minimized the time spent at each site (i. e., 10 minutes) and walked quickly among sites to lessen the chance of recounting the same individual (e.g., Lynch, 1995). We considered these relative abundances to be representative of how attractive a site was to adult dragonflies in compari- 
son to other sites. These site preferences may reflect differences in breeding opportunities at sites; however, there is mixed evidence as to whether visits to a site are reflective of mating opportunities and the success of eggs hatching into larvae. In some cases, the number of adult visits at a site has predicted larval communities (McCauley, 2006), whereas in others, the presence of adult dragonflies is not indicative of whether they will successfully reproduce at a location (Raebel et al., 2010). Indeed, the experimental ponds did not contain vegetation, and as a result, the design likely excluded the presence of larvae from endophytic dragonfly species.

\section{Statistical analysis}

We used generalized linear models (GLMs) to assess how connectivity to forest edges and source ponds was related to the abundance, species richness, and species diversity of dragonfly colonists at experimental ponds. Three separate GLMs tested the effect of forest connectivity and distance to source ponds on: (1) total dragonfly abundance across species using Poisson errors, (2) species richness using Poisson errors, and (3) Shannon diversity. One site was an outlier as the dragonfly abundance was more than 1.5 times the interquartile range above the third quartile (Crawley, 2007). Thus, the analysis of total dragonfly abundance was repeated minus this single outlier site to test the extent that this site affected the relationship between dragonfly abundance, forest connectivity and distance to source ponds. A distance-based redundancy analysis (db-RDA; vegan package; Oksanen et al., 2019) was performed, which tests the relationship between community composition and environmental variables (Legendre \& Anderson, 1999). In our case, the db-RDA tested the similarity in species abundances among sites in response to distance to source pond and forest connectivity. For the db-RDA, we removed species that only occurred at a single site (i. e., Sympetrum vicinum, Erythemis simplicicollis, and Epitheca cynosura), because their presence was not informative about the redundant patterns of community structure across sites (e.g., Hirst \& Jackson, 2007). We used a Gower index to assess dissimilarity among communities, as this index had the highest rank correlation among multiple dissimilarity indices. We determined $p$-values from a permutation test for the dbRDA using the 'anova' function. All analyses were conducted in R (version 3.5.2; R Core Team, 2018).

\section{Results}

A total of 134 dragonflies from 13 species were observed at the experimental ponds (Figure 2), including 12 individuals that could not be identified to species and three species of which one individual occurred at one site. The identified species differed in their relative abundance, with Libellula pulchella accounting for $34 \%$ of the total number of dragonflies observed $(n=46)$. Plathemis lydia, Libellula luctuosa, L. pulchella, and Anax junius were the most commonly observed species across sites (Figure 2). These four species have medium to large body sizes relative to the other dragonfly species observed. All observed species were libellulids, except for two aeshnids, A. junius and Aeshna canadensis, and the corduliid Epitheca cynosura. All these species are common in Ontario and have a 'secure' status in Ontario and Canada (i.e., are not at risk; Canadian Endangered Species Conservation Council, 2016).

The interaction between connectivity to forest edges and pond connectivity significantly predicted dragonfly abundance $\left(z_{5}=2.1, p=0.040\right)$. The greatest dragonfly abundance was predicted for sites both far from source ponds and close to forest edges. Similarly, when only the main effects were tested, both forest and pond connectivity significantly predicted dragonfly abundances $\left(z_{6}=3.1, p=\right.$ 0.0020 , Figure $3 \mathrm{a}$ and $z_{6}=3.1, p=0.0018$, Figure $3 \mathrm{~b}$, respectively). The significance of these effects appeared, however, to be driven by one site. When that site, which had the highest dragonfly abundance, was removed, neither connectivity to forest edges $\left(t_{5}=-0.27, p=0.79\right)$ nor to source ponds $\left(t_{5}=0.20, p=0.85\right)$ was a significant predictor of dragonfly abundance. Neither connectivity to forests nor distance to source ponds was related to the species richness of dragonflies at sites $\left(z_{6}=\right.$ 


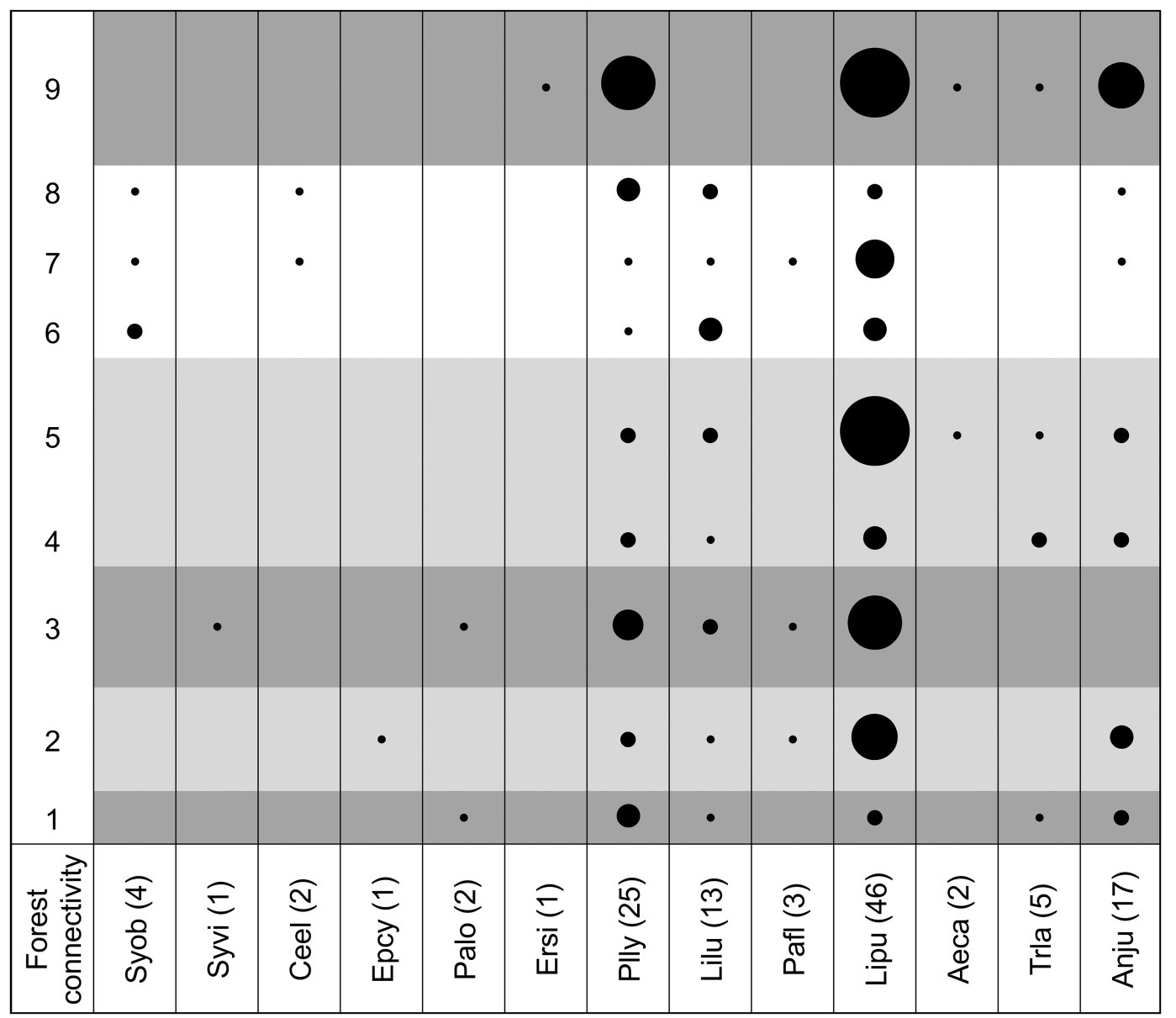

Figure 2. Relative species abundances (with abbreviated species names) at sites in response to increasing forest connectivity. Each row is a site, where 1 is the site least connected to forests and 9 is the most connected. White rows are sites closest to a source pond $(\sim 100 \mathrm{~m})$, light grey rows are a medium distance away $(\sim 200 \mathrm{~m})$, and dark grey rows are farthest away $(\sim 300 \mathrm{~m})$. Black circles indicate presence of a species at a site, and size of circles indicates the relative abundance of species across sites. Species are organized by hind wing length, a potential predictor of flight capacity (e. g., McCauley et al., 2014), from smallest (Sympetrum obtrusum) to largest (Anax junius). Species names are followed by total abundance in parentheses, and the abbreviations are as follows: Aeca = Aeshna canadensis, Anju = Anax junius, Ceel $=$ Celithemis elisa, Epcy = Epitheca cynosura, Ersi $=$ Erythemis simplicicollis, Lilu $=$ Libellula luctuosa, Lipu = Libellula pulchella, Pafl = Pantala flavescens, Palo = Pachydiplax longipennis, Plly $=$ Plathemis lydia, Syob = Sympetrum obtrusum, Syvi = Sympetrum vicinum, and Trla = Tramea lacerata.

$0.094, p=0.93$ and $z_{6}=0.21, p=0.84$, respectively) or the Shannon diversity of dragonfly visitors $\left(t_{6}=-0.49, p=0.64\right.$ and $t_{6}=-0.12, p=0.91$, respectively $)$.

There were some slight differences in community composition among sites. Some species were found across all sites (i. e., L. pulchella, P. lydia) or nearly all sites (i. e., L. luctuosa and A. junius; Figure 2). Most species, however, only visited a select set of sites (Figure 2): whether this was due to species-specific responses to forest connectivity and/or distance to source pond was unclear. Species generally clustered together on a db-RDA ordination plot (Figure $4 ; F_{2,6}=1.8, p=0.13$ ) with no response to either distance to source ponds $\left(F_{1,6}=2.4, p=0.064\right)$ or forest connectivity $\left(F_{1,6}=1.1\right.$, $p=0.39)$. Distance to source ponds loaded strongly on the first constrained axis $(0.96)$ and forest connectivity strongly on the second axis $(0.97)$ of the db-RDA, together explaining $37 \%$ of the variance in community composition. 
A

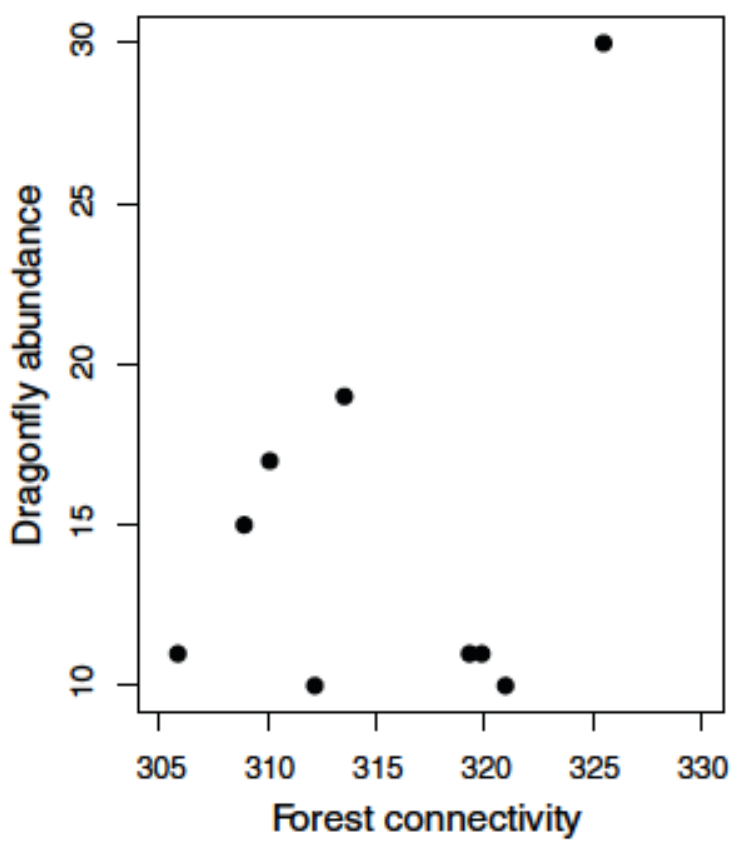

B

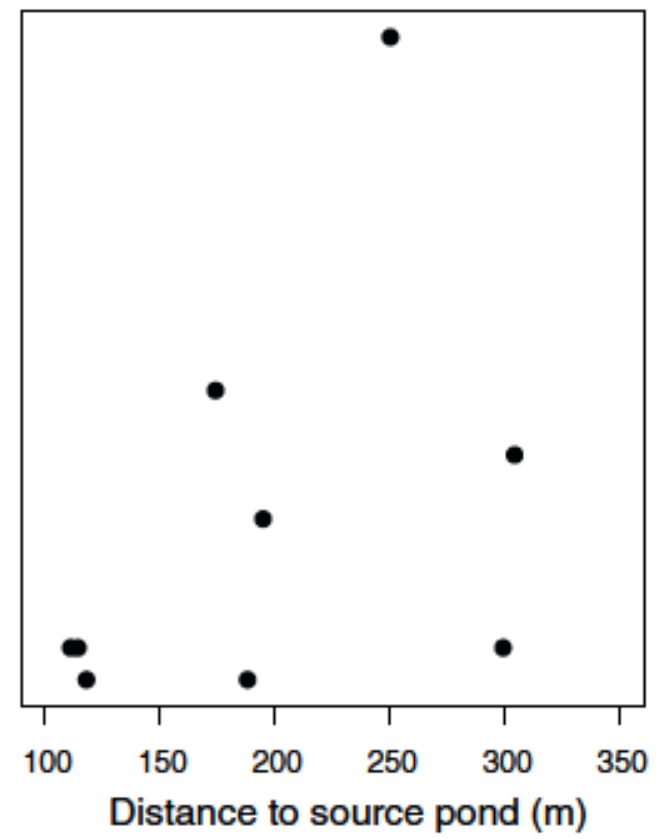

Figure 3. The effects of (A) forest connectivity and (B) distance to source pond $(\mathrm{m})$ on the abundance of dragonflies at sites.

\section{Discussion}

Neither degree of connectivity to forest edges nor proximity to source ponds predicted total dragonfly abundance or diversity at our experimental sites (Figures $3 \mathrm{a}$ and $3 \mathrm{~b}$ ). The site with the highest degree of connectivity to forest edges and one of the farthest away from the source ponds (i.e., the site situated $300 \mathrm{~m}$ from source ponds in the easternmost transect; see Figure 1) had the greatest abundance of dragonfly visitors, with both $A$. junius and $P$. lydia reaching their peak abundances at this site. However, we are reluctant to conclude that there is a significant effect of forest connectivity on dragonfly visits based on this single site, as removing it from our analysis resulted in no trend between abundance and forest connectivity or distance to source ponds, and these factors had no influence on species richness or Shannon diversity. Without additional sites spanning a greater range of forest connectivity, we cannot ascertain whether there was indeed a threshold of forest connectivity above which dragonflies would demonstrate a strong preference for a pond. However, if there were such a threshold, there would be a non-linear relationship between forest connectivity and dragonfly preference for ponds, as too much surrounding forest cover and/or overhanging pond canopy cover would make ponds less attractive (Chin \& Taylor, 2009; French \& McCauley, 2018). The perceptual range of dragonflies has also not been explicitly studied, particularly for landscape elements like forests that do not reflect substantial light (see Bemáth et al., 2002). As a result, we do not know the spatial limitations of dragonflies' ability to perceive forest edges.

Although our study had a limited number of total sites available, which resulted in low statistical power to detect significant pattems, we observed 137 dragonflies from 13 species. Previous surveys of the same source ponds used in our study resulted in the detection of 11 species from July-August, 2013 (Gazebo Pond) and 8 species from July-September, 2014 (Bam Pond; French \& McCauley, 2018), which were a subset of the species found in our surveys. This suggests that we accurately characterized the local dragonfly community found during our study period. We did not expect distance to source ponds to limit the arrival of dragonflies at the experimental ponds, due to the good dispersal abilities of the dragonfly species observed in our study (i. e., $415-1886 \mathrm{~m}$ for seven of the 


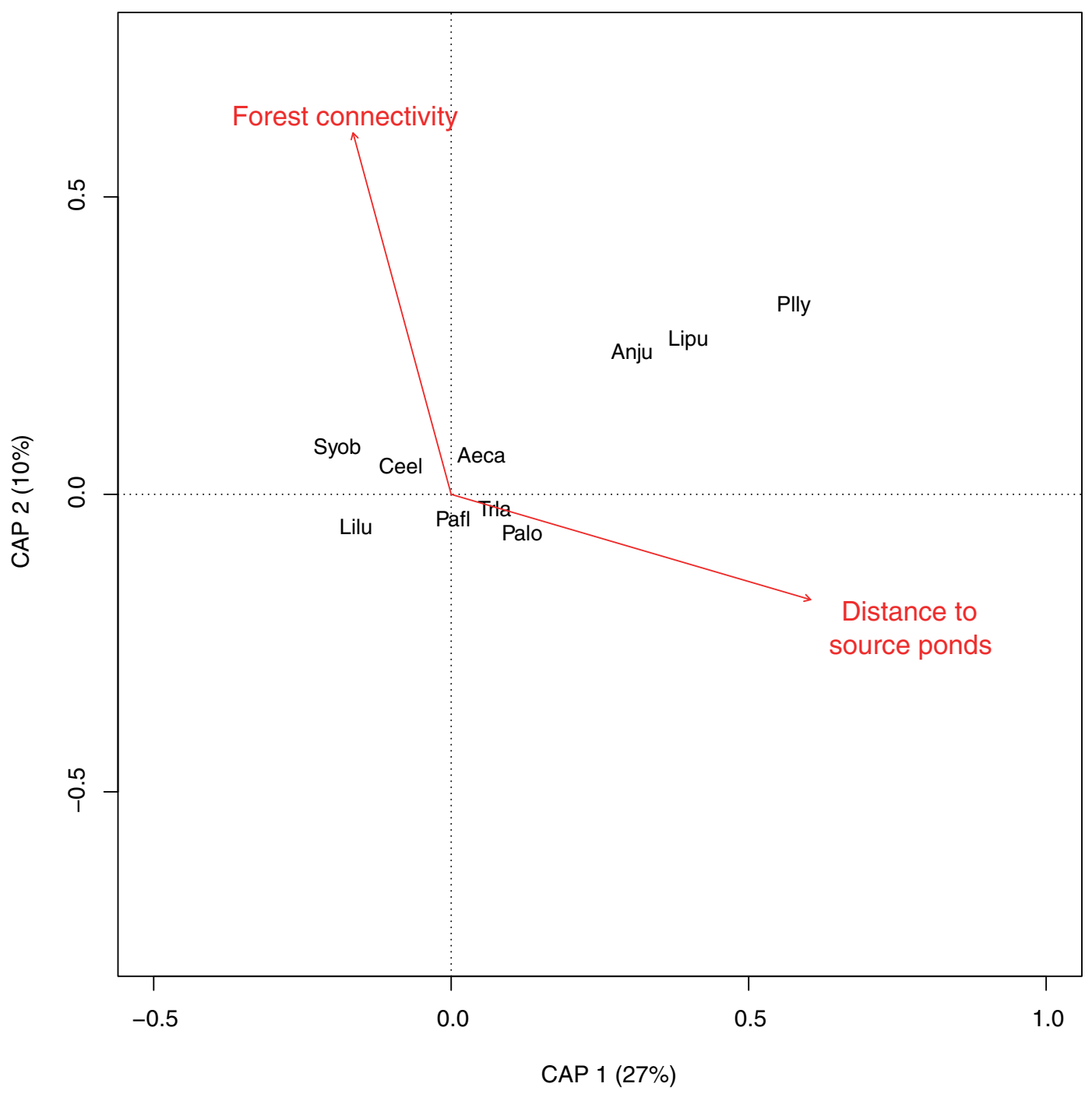

Figure 4. Ordination plot of a distance-based redundancy analysis (db-RDA) showing the relationship between community composition and both forest connectivity and distance to source ponds. The first constrained db-RDA axis (CAP 1) was more associated with distance to source ponds (0.96), whereas the second db-RDA axis (CAP 2) was more associated with forest connectivity (0.97). Four letter codes are dragonfly species' names; refer to the Figure 2 caption for full species names.

thirteen species observed here; McCauley, unpublished data but synthesized in McCauley, 2006, 2007), and the relatively short distances to the source ponds (i.e., 111-304 m). This prediction was supported by our data only when an outlier was excluded. However, we also did not detect an effect of forest connectivity on dragonfly arrival when this outlier was removed, suggesting that even if dragonflies are using forest edges for roosting, the edges were close enough to our experimental ponds so as not to impact dragonfly arrival. Non-migratory dragonflies are more likely to move or disperse across short distances (e.g., <100 m; McCauley, 2006; $125 \mathrm{~m}$, Chin \& Taylor, 2009), but can move over 50-200 m on a daily basis (Bried \& Ervin, 2006; Eason \& Switzer, 2006) and can disperse several hundred metres to reproductive habitats (McCauley, 2007). Some larger and/or migratory species likely cover even greater distances; for example, Macromia taeniolata and the migratory Anax junius can cover approximately $2 \mathrm{~m} \mathrm{~s}^{-1}$ (May, 1991). Although driven by an outlier and thus inconclusive, the most prominent trends in the data were the effects of distance to source pond and forest connectivity on dragonfly abundance, with $A$. junius and $P$. lydia visiting this distant site near the forest edge more than any other site. Anax junius individuals in particular are commonly 
found roosting in both open habitats and low in trees (Paulson, 2011), in part due to their large size and 'flier' status (i.e., flying instead of perching when active), and have also been found to roost along forest edges facing a westerly direction, which is the case at this site (Corbet, 2004). Plathemis lydia males are very territorial (Paulson, 2011), and a site located farther away from the source pond may have given them more of an opportunity to find new territories.

Although we did not detect a relationship between connectivity to forest and the abundance, species richness, or species diversity of dragonflies arriving at our experimental ponds, forests may still influence the arrival at aquatic habitats of other dragonfly species that use forest edges more extensively for roosting and foraging. For these species, having nearby forest edges could minimize the time and energy needed to travel between these habitats and reproductive aquatic habitats, particularly if they are not good dispersers. Alternatively, given the close proximity of all of our experimental ponds to at least some forest edge, connectivity to these forest environments may not have been limiting for the dragonflies found at our sites, if these species use forest edges at all. Each site was within $10-79 \mathrm{~m}$ of a forest edge, with seven out of nine sites being less than $50 \mathrm{~m}$ away, a distance that dragonflies can cover on a daily basis (Bried \& Ervin, 2006; Eason \& Switzer, 2006). During our study, we observed dragonflies moving readily through the open field matrix from experimental ponds to the nearest forest edge. Adult dragonflies may therefore make small-scale movements to forest edges for roosting and foraging (Corbet, 2004; Timofeev, 2016) but avoid forests and forest edges in favour of open environments during movement and dispersal (Chin \& Taylor, 2009; French $\&$ McCauley, 2019). In addition, tree canopy cover that overhangs aquatic habitats limits the detection of habitats by adult dragonflies (Remsburg et al., 2008; French \& McCauley, 2018), and those that do arrive have a more limited prey base due to reduced primary productivity in closed habitats (Schiesari, 2006). These studies taken together suggest that dragonflies in temperate regions have a complex relationship with forests and forest edges. Forests may impede movement and dispersal as a structural barrier at larger spatial scales, and forests that are directly adjacent to ponds may make ponds unattractive to adult dragonflies; however, forests may offer supporting habitat when located at more intermediate spatial scales.

There were no differences among species in their preferences for experimental ponds with varying degrees of connectivity to forest edges or source ponds (Figures 2 and 4). All the species observed in our study were common to the region (Canadian Endangered Species Conservation Council, 2016) and good dispersers (McCauley, 2006, 2007). Aeshnids, corduliids, and libellulids have all been observed roosting along forest edges (Corbet, 2004; Timofeev, 2016), so they might use forest edges to equal degrees while roosting. To what degree they partition the three-dimensional space at a forest edge for roosting (i. e., height, width, and depth) is relatively unexplored, although larger dragonflies have been observed to roost higher in trees than the smaller libellulids (Corbet, 2004). Some dragonfly families use forest edges to a greater extent while foraging: aeshnids and corduliids fly farther and for longer along forest edges, whereas libellulids tend to perch in more open areas including at aquatic habitats (Corbet, 2004; Corbet \& May, 2008). Three of our most commonly observed libellulid species likely do not forage along forest edges, and our other observed species, with the exception of A. junius, were rare across all sites, which may have diminished our ability to detect community differences based on foraging habitat. The larvae of many of the species we observed are generally found in more open canopy aquatic habitats, although the adults of these species use forests and forest edges to varying degrees (Table 1). Therefore, although we did not detect an effect of forest edges on how the dragonfly community at our experimental ponds assembled, forest edges may still be important landscape features for some dragonfly species. As a result, diversity in dragonfly communities may be enhanced by the presence of a mosaic of terrestrial environments, with open and forested environments having a combination of risks and benefits.

Our results suggest that newly created ponds that are relatively close to source ponds and located in open terrestrial environments will readily attract dispersing dragonflies. The position of these experimental ponds with respect to forest edges did not generally affect community assembly. Whether this would remain true with respect to other dragonfly assemblages (e.g., with more aeshnid species that may use forest edges to a greater degree; Paulson, 2011) or those located in other regions is unknown, as is whether other odonates such as damselflies that have poorer dispersal abilities (e.g., Angelibert \& Giani, 2003) may be more limited by forest edge availability (e.g., Watanabe et al., 1987). Different assembly patterns might also be detected in landscapes where ponds are located farther away from forest edges, making it more energetically costly to move between forest and re- 
Table 1. List of species of adult dragonflies found during our surveys, and their preferences for open versus closed habitats during their larval stage ${ }^{1}$ (i.e., canopy cover over a pond) and during their adult $\operatorname{stage}^{2}$ (i.e., use of trees, forest edges, or forests for roosting, foraging, and flight). ${ }^{1}$ McCauley et al. (2008), 2Paulson (2009, 2011).

\begin{tabular}{lll}
\hline Species & Larval stage $^{\mathbf{1}}$ & Adult stage $^{2}$ \\
\hline Aeshna canadensis & Open and closed Open and closed \\
Anax junius & Open and closed Open and closed \\
Celithemis elisa & Open & Open \\
Epitheca cynosura & Open & Open and closed \\
Erythemis simplicicollis & Open & Open \\
Libellula luctuosa & Open & Open and closed \\
Libellula pulchella & Open & Open \\
Pachydiplax longipennis & Open & Open and closed \\
Pantala flavescens $*$ & Unknown & Open and closed \\
Plathemis lydia & Open & Open and closed \\
Sympetrum obtrusum & Open and closed Open and closed \\
Sympetrum vicinum & Open and closed Open and closed \\
Tramea lacerata & Open & Open \\
\hline
\end{tabular}

*also attracted to new habitats

productive habitats. Rather than needing a greater amount of accessible forest edge, dragonflies may instead depend on one particular stretch of forest edge habitat that offers optimal refuge, such as an edge that provides a wind barrier or access to more favourable microhabitat temperatures (Corbet, 2004). Since forest edges were not important at our spatial scale for adult dragonflies choosing aquatic habitats, the proximity of forest edges may not be necessary to consider when creating or restoring aquatic habitats for the purposes of attracting dragonflies. For taxa that depend on similar or different surrounding landscape elements (e.g., Cormont et al., 2016), habitat patches could be created in a landscape that already has valuable landscape elements, or else restored by adding these landscape elements around habitat patches. A consideration of how different landscape elements impact organismal behaviour and species' distributions can better inform and direct habitat conservation efforts.

Full dataset available from http://dx.doi.org/10.17632/fh4jz45yft.3.

\section{Acknowledgements}

We thank the Koffler Scientific Reserve, S. Schneider, M. Cumming, and J. Jensen for their assistance in creating these ponds and facilitating this research. Thank you to H. Wagner and anonymous reviewers for their comments on earlier drafts of this manuscript, and L. Rowe, B. Gilbert, M. Krkošek, and J. Stinchcombe for their valuable contributions to the design and construction of the experimental pond array. Pond construction was funded by awards to SJM from the Canadian Foundation for Innovation, John R. Evans Leaders Fund and the Ontario Research Fund, and the Leaders Opportunity Fund. LMSNL acknowledges the CAPES Foundation (scholarship no. 88888.0130692013-00). Additional research funding for this work was provided by the Department of Biology at the University of Toronto Mississauga and an NSERC Discovery Grant (RGPIN 435614) to SJM. 


\section{References}

Angelibert, S. \& Giani, N. (2003). Dispersal characteristics of three odonate species in a patchy habitat. Ecography, $26,13-20$. https://doi.org/10.1034/j.1600-0587.2003.03372.x

Baguette, M. \& Van Dyck, H. (2007). Landscape connectivity and animal behavior: functional grain as a key determinant for dispersal. Landscape Ecology, 22, 1117- 1129. https://doi.org/10.1007/s10980-007-9108-4

Bernáth, B., Szedenics, G., Wildermuth, H. \& Horváth, G. (2002). How can dragonflies discern bright and dark waters from a distance? The degree of polarisation of reflected light as a possible cue for dragonfly habitat selection. Freshwater Biology, 47, 1707-1719. https://doi.org/10.1046/j.1365-2427.2002.00931.x

Brand, L. A. \& George, T. L. (2001). Response of passerine birds to forest edge in coast redwood forest fragments. The Auk, 118, $678-686$. https://doi.org/10.1093/auk/118.3.678

Bried, J. T. \& Ervin, G. N. (2006). Abundance patterns of dragonflies along a wetland buffer. Wetlands, 26, 878 883.

Canadian Endangered Species Conservation Council (2016). Wild Species 2015: The General Status of Species in Canada. National General Status Working Group.

Chardon, J. P., Adriaensen, F. \& Matthysen, E. (2003). Incorporating landscape elements into a connectivity measure: a case study for the Speckled wood butterfly (Pararge aegeria L.). Landscape Ecology, 18, 561- 573. https://doi.org/10.1023/A:1026062530600

Chin, K. S. \& Taylor, P. D. (2009). Interactive effects of distance and matrix on the movements of a peatland dragonfly. Ecography, 32, $715-722$. https://doi.org/10.1111/j.1600-0587.2009.05744.x

Corbet, P. S. (2004). Dragonflies: behavior and ecology of Odonata (revised ed.). Colchester, UK: Harley Books.

Corbet, P. S. (2006). Forests as habitats for dragonflies (Odonata). In A. Cordero-Rivera (Ed.), Forests and Dragonflies, pp. 13 - 36. Pensoft Publishers, Sofia, Bulgaria.

Corbet, P. S. \& May, M. L. (2008). Fliers and perchers among Odonata: dichotomy or multidimensional continuum? A provisional reappraisal. International Journal of Odonatology, 11, 155-171. https://doi.org/10.1080/13887890.2008.9748320

Cormont, A., Siepel, H., Clement, J., Melman, T. C. P., WallisDeVries, M. F., van Turnhout, C. A. M., Sparrius, L. B., Reemer, M., Biesmeijer, J. C., Berendse, F. \& de Snoo, G. R. (2016). Landscape complexity and farmland biodiversity: evaluating the CAP target on natural elements. Journal for Nature Conservation, 30, $19-26$. https://doi.org/10.1016/j.jnc.2015.12006

Crawley, M. J. (2007). The R Book. Chichester, UK: John Wiley \& Sons. https://doi.org/10.1002/9780470515075

Damschen, E. I., Haddad, N. M., Orrock, J. L., Tewksbury, J. J. \& Levey, D. J. (2006). Corridors increase plant species richness at large scales. Science, $313,1284-1286$. https://doi.org/10.1126/science. 1130098

Debinski, D. M., Ray, C. \& Saveraid, E. H. (2001). Species diversity and the scale of the landscape mosaic: do scales of movement and patch size affect diversity? Biological Conservation, 98, 179-190. https://doi.org/10.1016/S0006-3207(00)00153-1

Donald, P. F. \& Evans, A. D. (2006). Habitat connectivity and matrix restoration: the wider implications of agrienvironment schemes. Journal of Applied Ecology, 43, $209-218$. https://doi.org/10.1111/j.1365-2664.2006.01 146.x

Dunkle, S. W. (2000). Dragonflies through binoculars: a field guide to dragonflies of North America. Oxford, UK: Oxford University Press.

Eason, P. K. \& Switzer, P. V. (2006). Spatial learning in dragonflies. International Journal of Comparative Psychology, 19, $268-281$.

Eycott, A. E., Stewart, G. B., Buyung-Ali, L. M., Bowler, D. E., Watts, K. \& Pullin, A. S. (2012). A meta-analysis on the impact of different matrix structures on species movement rates. Landscape Ecology, 27, $1263-1278$. https://doi.org/10.1007/s10980-012-9781-9

Fahrig, L. (2001). How much habitat is enough? Biological Conservation, 100, $65-74$. https://doi.org/10.1016/S0006-3207(00)00208-1

French, S. K. \& McCauley, S. J. (2018). Canopy cover affects habitat selection by adult dragonflies. Hydrobiologia, 818, 129 - 143. https://doi.org/10.1007/s10750-018-3600 - 5

French, S. K. \& McCauley, S. J. (2019). The movement responses of three libellulid dragonfly species to open and closed landscape cover. Insect Conservation and Diversity, 12, 437-447. https://doi.org/10.1111/icad.12355

Goodwin, B. J. \& Fahrig, L. (2002). How does landscape structure influence landscape connectivity. Oikos, 99, $552-$ 570. https://doi.org/10.1034/j.1600-0706.2002.11824.x

Haddad, N. M., Brudvig, L. A., Clobert, J., Davies, K. F., Gonzalez, A., Holt, R. D., Lovejoy, T. E., Sexton, J. O., Austin, M. P., Collins, C. D., Cook, W. M., Damschen, E. I., Ewers, R. M., Foster, B. L., Jenkins, C. N., King, A. J., Laurance, W. F., Levey, D. J., Margules, C. R., Melbourne, B. A., Nicholls, A. O., Orrock, J. L., Song, D.-X. 
\& Townshend, J. R. (2015). Habitat fragmentation and its lasting impact on Earth's ecosystems. Science Advances, 1, e1500 052. https://doi.org/10.1126/sciadv.1500052

Hanski, I. (1994). A practical model of metapopulation dynamics. Journal of Animal Ecology, 63, 151-162. https:// doi.org/10.2307/5591

Haslem, A. \& Bennett, A. F. (2008). Birds in agricultural mosaics: the influence of landscape pattern and countryside heterogeneity. Ecological Applications, 18, 185 - 196. https://doi.org/10.1890/07-0692.1

Hirst, C. N. \& Jackson, D. A. (2007). Reconstructing community relationships: the impact of sampling error, ordination approach, and gradient length. Diversity and Distributions, 13, 361-371. https://doi.org/10.1111/j.14724642.2007.00307.x

Johansson, F. \& Brodin, T. (2003). Effects of fish predators and abiotic factors on dragonfly community structure. Journal of Freshwater Ecology, 18, 415 - 423. https://doi.org/10.1080/02705 060.2003.9663977

Kadoya, T. \& Washitani, I. (2012). Use of multiple habitat types with asymmetric dispersal affects patch occupancy of the damselfly Indolestes peregrinus in a fragmented landscape. Basic and Applied Ecology, 13, $178-187$. https://doi.org/10.1016/j.baae.2012.02004

Keller, D., Van Strien, M. J. \& Holderegger, R. (2012). Do landscape barriers affect functional connectivity of populations of an endangered damselfly? Freshwater Biology, 57, 1373 - 1384. https://doi.org/10.1111/j.1365 - 2427. 2012.02797.x

Kupfer, J. A., Malanson, G. P. \& Franklin, S. B. (2006). Not seeing the ocean for the islands: the mediating influence of matrix-based processes on forest fragmentation effects. Global Ecology and Biogeography, 15, 8-20. https:// doi.org/10.1111/j.1466-822X.2006.00204.X

Legendre, P. \& Anderson, M. J. (1999). Distance-based redundancy analysis: testing multispecies responses in multifactorial ecological experiments. Ecological Monographs, 69, 1-24. https://doi.org/10.1890/0012 - 9615(1999) 069[0001:DBRATM]2.0.CO;2

Lynch, J. F. (1995). Effects of point count duration, time-of-day, and aural stimuli on detectability of migratory and resident bird species in Quintana Roo, Mexico. In C. J. Ralph, J. R. Sauer \& S. Droege (Eds.), Monitoring bird populations by point counts (Report No. PSW-GTR-149), pp. 1-6. Albany, CA: Pacific Southwest Research Station, Forest Service, U.S. Department of Agriculture.

MacArthur, R. H. \& Wilson, E. O. (1967). The theory of island biogeography. Princeton, NJ: Princeton University Press.

May, M. L. (1991). Dragonfly flight: power requirements at high speed and acceleration. Journal of Experimental Biology, 158, 325-342.

McCauley, S. J. (2006). The effects of dispersal and recruitment limitation on community structure of odonates in artificial ponds. Ecography, 29, 585 - 595. https://doi.org/10.1111/j.0906-7590.2006.04 787.x

McCauley, S. J. (2007). The role of local and regional processes in structuring larval dragonfly distributions across habitat gradients. Oikos, 116, $121-133$. https://doi.org/10.1111/j.2006.0030-1299.15105.x

McCauley, S. J., Davis, C. J., Relyea, R. A., Yurewicz, K. L., Skelly, D. K. \& Werner, E. E. (2008). Metacommunity patterns in larval odonates. Oecologia, 158, 329-342. https://doi.org/10.1007/s00442-008-1141-8

McCauley, S. J., Davis, C. J., Werner, E. E. \& Robeson, M. S. II (2014). Dispersal, niche breadth and population extinction: colonization ratios predict range size in North American dragonflies. Journal of Animal Ecology, 83, 858 -865. https://doi.org/10.1111/1365-2656.12 181

Mead, K. (2003). Dragonflies of the North Woods. Duluth: Kollath-Stensaas Publishing.

Morris, A. D., Miller, D. A. \& Kalcounis-Rueppell, M. C. (2010). Use of forest edges by bats in a managed pine forest landscape. Journal of Wildlife Management, 74, 26 - 34. https://doi.org/10.2193/2008 - 471

Oksanen, J., Blanchet, F. G., Friendly, M., Kindt, R., Legendre, P., McGlinn, D., Minchin, P. R., O’Hara, R. B., Simpson, G. L., Solymos, P., Stevens, M. H. H., Szoecs, E. \& Wagner, H. (2019). Vegan: community ecology package. R package version $2.5-5$.

Paulson, D. (2009). Dragonflies and Damselflies of the West. Princeton, NJ: Princeton University Press. https://doi. org/10.1515/9781400832941

Paulson, D. (2011). Dragonflies and Damselflies of the East. Princeton, NJ: Princeton University Press.

Prugh, L. R., Hodges, K. E., Sinclair, A. R. E. \& Brashares, J. S. (2008). Effect of habitat area and isolation on fragmented animal populations. PNAS, 105, 20770 - 20775. https://doi.org/10.1073/pnas.0806080 105

R Core Team (2018). R: a language and environment for statistical computing. Vienna, Austria: R Foundation for Statistical Computing.

Raebel, E. M., Merckx, T., Riordan, P., Macdonald, D. W. \& Thompson, D. J. (2010). The dragonfly delusion: why it is essential to sample exuviae to avoid biased surveys. Journal of Insect Conservation, 14, 523 - 533. https://doi. org/10.1007/s10841-010-9281-7

Remsburg, A. J., Olson, A. C. \& Samways, M. J. (2008). Shade alone reduces adult dragonfly (Odonata: Libellulidae) abundance. Journal of Insect Behavior, 21, 460 - 468. https://doi.org/10.1007/s10 $905-008$ - 9138-z

Ricketts, T. H. (2001). The matrix matters: effective isolation in fragmented landscapes. The American Naturalist, 158, 87 - 99. https://doi.org/10.1086/320 863

Schiesari, L. (2006). Pond canopy cover: a resource gradient for anuran larvae. Freshwater Biology, 51, $412-423$. https://doi.org/10.1111/j.1365-2427.2005.01497.x

Schindelin, J., Arganda-Carreras, I., Frise, E., Kaynig, V., Longair, M., Pietzsch, T., Preibisch, S., Rueden, C., Saalfeld, S., Schmid, B., Tinevez, J.-Y., White, D. J., Hartenstein, V., Eliceiri, K., Tomancak, P. \& Cardona, A 
(2012). Fiji - an open source platform for biological image analysis. Nature Methods, 9, 676-682. https://doi. org/10.1038/nmeth.2019

Schlinkert, H., Ludwig, M., Batáry, P., Holzschuh, A., Kovács-Hostyánszki, A., Tscharntke, T. \& Fischer, C. (2016) Forest specialist and generalist small mammals in forest edges and hedges. Wildlife Biology, 22, 86-94. https:// doi.org/10.2981/wlb.00176

Timofeev, A. N. (2016). The ecology and behavioral features of dragonflies (Insecta, Odonata) in the forest-steppe zone of Central Chernozem region. Russian Journal of Ecology, 47, 501- 507. https://doi.org/10.1134/S106741361605012X

Watanabe, M., Ohsawa, N. \& Taguchi, M. 1987. Territorial behaviour in Platycnemis echigoana Asahina at sunflecks in climax deciduous forests (Zygoptera: Platycnemididae). Odonatologica, 16, 273 - 280.

Wiens, J. A. (2002). Central concepts and issues of landscape ecology. In K. J. Gutzwiller (Ed.), Applying landscape ecology in biological conservation, pp. $3-21$. New York, NY: Springer https://doi.org/10.1007/978-1-4613-0059-5_1 